Int. J. Morphol.,

33(3):902-907, 2015.

\title{
Densitometric Analysis of the Human Ulna
}

\author{
Análisis Densitométrico de la Ulna Humana
}

\author{
S. Aguado-Henche*; C. Clemente de Arriba* \& J. Carrascosa-Sánchez*
}

\begin{abstract}
AGUADO-HENCHE, S.; CLEMENTE DE ARRIBA, C. \& CARRASCOSA-SÁNCHEZ, J. Densitometric analysis of the human ulna. Int. J. Morphol., 33(3):902-907, 2015.

SUMMARY: This study describes the distribution of the normal bone mass in the mature human ulna, as knowledge of distribution may provide information to orthopaedic surgeons for the treatment of such fractures while advancing the understanding of the responses of osteosynthesis elements during bone repair. A random sample of 41 dry ulnas was studied with a DXA system using a Norland XR-26 densitometer. Two projections were performed, lateral and antero-posterior. In both projections five regions of interest (ROI) were selected: proximal (ROI 1), proximal-intermediate (ROI 2), intermediate (ROI 3), distal-intermediate (ROI 4) and distal (ROI 5). All statistical calculations were performed using Stat graphics Plus (version 5.1) and SPSS (version 15.0). Bone mineral density (BMD) and bone mineral content (BMC) were calculated. Paired data were analysed using parametric Student t-Test to compare BMD and BMC in every region in both projections. DXA show that the higher BMD is in the proximal-intermediate region (ROI 2). The higher BMC is found in the proximal region (ROI 1). Lower BMD and BMC are found in the distal region (ROI 5). The total BMD shows significant statistical differences $(\mathrm{p} \leq 0.001)$, which indicates the heterogeneous nature of the distribution of bone mass in the studied bone. Bone densitometry, measured by the DXA technique, is useful for assessing trabecular architecture of the human ulna.
\end{abstract}

KEY WORDS: Densitometry; Ulna; Bone mineral density; Bone mineral content; Elbow.

\section{INTRODUCTION}

Dual energy X-ray absorptiometry (DXA) has been used for the study of dry bones such as the spine, femur, mandible, etc. to detect initial appearances of ossification centers; in clinical practice, DXA is widely used for the diagnosis and evaluation of osteoporosis and a new generation of DXA scanners offer software for performing vertebral morphometric analysis (Blake \& Fogelman, 1997). Furthermore, numerous bone analyses have been performed on experimental animals using DXA (Tsujio et al., 2009).

The anatomy of the human ulna has been previously described (Windisch et al., 2007). Yet studies of the spatial distribution of bone mineral density (BMD) in the entire bone, reflecting its morphological pattern, are scarce (Fernandez Camacho et al., 1996). Also, few studies have examined the anthropometric characteristics of the human ulna (Goldberg et al., 2007; Wahner et al., 1985).

Bone density initially adapts to external loads during growth phases while the trabecular architecture is acquired later during development (Tanck et al., 2001). It is common knowledge that the osteogenic effect of a force is produced on the specific site of its application, both in young and mature bones (Heinonen et al., 2001), in direct proportion to its intensity (Hsieh \& Turner, 2001).

Therefore, trabecular pattern is directly related to the loads supported by the bone and thus, fractures may occur from traumas. For this reason, our study describes the distribution of the normal bone mass in the mature human ulna, as knowledge of this distribution may provide information to orthopaedic surgeons for the treatment of such fractures while advancing the understanding of the responses of osteosynthesis elements during bone repair.

\section{MATERIAL AND METHOD}

A random sample of 58 dry right ulnae from the skeletal collection of the Department of Surgery, Anatomy and Social Medical Sciences of the University of Alcalá was studied, excluding 17 bones presenting alterations or damage, (conservation damage resulting in cortical bone loss, previously evident pathologies, or any other cause that may alter or impede proper analysis and thereby distort the 
results). All of the bones came from adult human skeletons, having completed the bone growth and development stages.

A Norland XR-26 densitometer, software 2.5 (Norland Co., Fort Atkinson, WI, USA; Emsor SA, Madrid) was used for all studies with an investigation mode. Each scan session was preceded by a calibration routine using a standard calibration block supplied by the manufacturer. All of the ulnae used in the study came from cemetery ossuaries. They were donated voluntarily by the authorities to Alcalá Medical School.

The bone is first centered on the examining board. Stability should be ensured in order to prevent variation in position during the study. Cotton gauze may be used for optimal stabilization. The bones are directly exposed, without water or any other materials that may resemble soft tissue.

For the densitometric analysis of the human ulna structure, two projections were performed: lateral and anteroposterior. For the two position study, the reference is the ridge of the trochlear notch (incisura trochlearis) which corresponds to the sulcus of the humeral trochlea (GómezOliveros, 1962).

* Anteroposterior Position: The axis of the ridge of the trochlear notch is perpendicular to the axis of the examining board.

* Lateral Position: The axis of the ridge of the trochlear notch is parallel to the axis of the examining board.

To begin the scan, the starting point was placed $0.5 \mathrm{~cm}$ directly above the proximal extremity. A baseline point was marked below the distal extremity. A third point (goal line) was marked at $1 \mathrm{~cm}$ from the more lateral part of the bone.

This technique offers a high degree of accuracy and precision, approaching $1 \%$. The scanning speed was $60 \mathrm{mms}$, with an interlinear space of $1 \mathrm{~mm}$ and point by point resolution of $1 \mathrm{~mm}$ horizontal x $1 \mathrm{~mm}$ vertical. The defined exploration was completed as outlined, in an average time of 10-15 min. Scan acquisition and scan analyses were performed by one researcher (Fig. 1).

Dry ulna calculations were performed for the following magnitudes:

BMD: Bone mineral density, in $\mathrm{g} / \mathrm{cm}^{2}$.

BMC: Bone mineral content, in grams. BMC is defined as the mineral mass contained in an entire bone or the mineral mass per unit bone length. Bone mineral content is obviously a size-dependent parameter (Schoenau et al., 2004).
Area: Measured area, in square centimetres $(\mathrm{cm} 2)$. Length: Total bone length, in centimetres $(\mathrm{cm})$. Width: Total bone width, in centimetres $(\mathrm{cm})$.

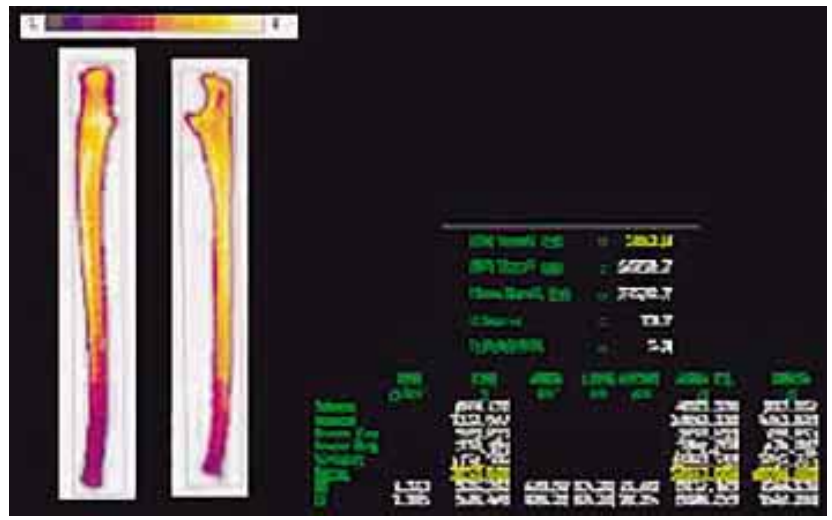

Fig. 1. Densitometric image of the ulna.

For the purpose of this survey, in both projections five equal regions of interest (ROI) were selected: proximal (ROI-1), proximal-intermediate (ROI-2), intermediate (ROI3 ), distal-intermediate (ROI-4) and distal (ROI-5). Specific system software 1 of the equipment divides the total bone length in the number of regions that we indicate. The total region corresponded to the overall area of the bone's length and height (Fig. 2).
L.

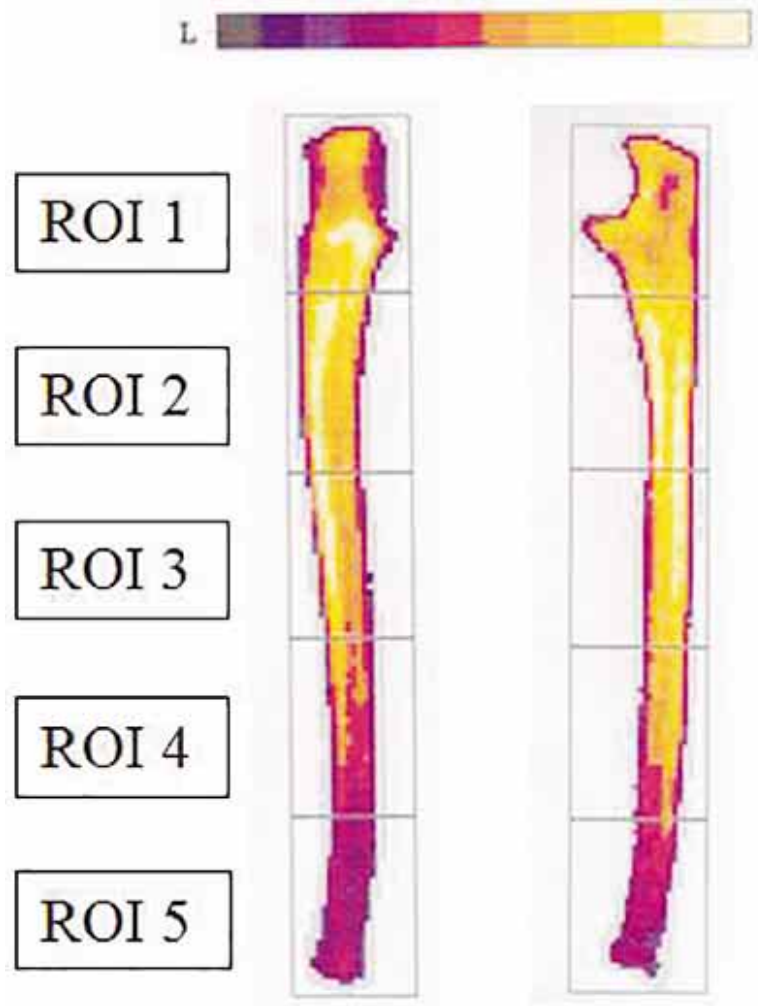

Fig. 2. Regions of interest. 
All statistical calculations were performed using Statgraphics Plus (version 5.1) and SPSS (Statistical Package for Social Sciences), version 15.0. From the data collected, descriptive statistics were obtained for the concentration and dispersion of BMD and BMC, the number of cases, mean, standard deviation and standard error of the mean for results evaluation. BMD and BMC of the various regions of the ulna in the two projections were compared using the Student's t test for paired samples.

This study was approved by the Office of Research Risk Protection of Alcalá Medical School.

Table I. Descriptive statistics of the total ulna in both projections $(n=41)$.

\begin{tabular}{lcc}
\hline & $\boldsymbol{A P}$ & $\boldsymbol{L A} \boldsymbol{T}$ \\
\hline Total BMD & $0.69 \pm 0.14$ & $0.67 \pm 0.14$ \\
Total BMC & $28.75 \pm 8.63$ & $28.72 \pm 8.50$ \\
Total Area & $41.05 \pm 5.70$ & $41.84 \pm 5.25$ \\
Total Length & $24.51 \pm 1.66$ & $24.50 \pm 1.66$ \\
Total Width & $3.35 \pm 0.40$ & $4.08 \pm 0.59$ \\
\hline
\end{tabular}

Values are the Means $\pm S D$. Area in $\mathrm{cm}^{2}$. Length in $\mathrm{cm}$.

\section{RESULTS}

Tables I and II show the statistic descriptions of the densitometry variables examined in both projections. Table III shows BMD and BMC values for the five regions of interest. DXA reveals that the higher BMD is found in the proximal-intermediate region (ROI 2) (Fig. 3). The higher $\mathrm{BMC}$ is found in the proximal region (ROI 1), which

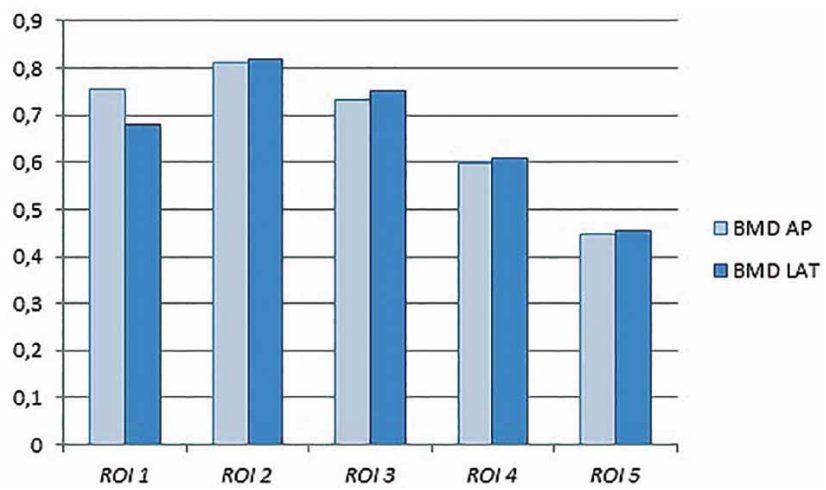

Fig. 3. Regional BMD in both projections. Values in grams $/ \mathrm{cm} 2$.

Table II. Descriptive statistics of the Regions in both projections $(\mathrm{n}=41)$.

\begin{tabular}{lccccc}
\hline & ROI 1 & ROI 2 & ROI 3 & ROI 4 & ROI 5 \\
\hline AP - Area & $10.58 \pm 1.57$ & $9.08 \pm 1.33$ & $8.12 \pm 1.42$ & $7.02 \pm 1.01$ & $6.22 \pm 0.94$ \\
AP - Length & $4.88 \pm 0.33$ & $4.88 \pm 0.33$ & $5.03 \pm 0.41$ & $4.88 \pm 0.33$ & $4.88 \pm 0.33$ \\
LAT - Area & $11.68 \pm 1.52$ & $8.94 \pm 1.24$ & $8.09 \pm 1.07$ & $6.98 \pm 0.82$ & $6.24 \pm 1.00$ \\
LAT - Length & $4.88 \pm 0.33$ & $4.88 \pm 0.33$ & $5.03 \pm 0.43$ & $4.88 \pm 0.33$ & $4.88 \pm 0.33$ \\
\hline
\end{tabular}

Values are the Means \pm SD. Area in $\mathrm{cm}^{2}$. Length in $\mathrm{cm}$.

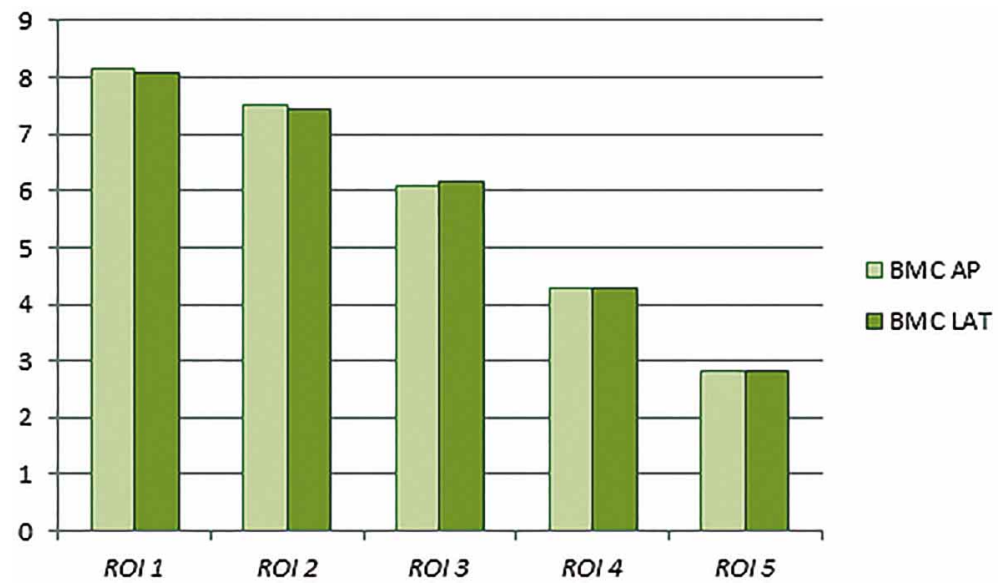

Fig. 4. Regional BMC in both projections. Values in grams.

Table III. BMD and BMC of the Regions in both projections $(\mathrm{n}=41)$.

\begin{tabular}{lccccccccccc}
\hline & \multicolumn{2}{c}{ ROI 1 } & \multicolumn{2}{c}{ ROI 2 } & \multicolumn{2}{c}{ ROI 3 } & \multicolumn{2}{c}{ ROI 4 } & \multicolumn{2}{c}{ ROI 5 } \\
\cline { 2 - 12 } & $\boldsymbol{A P}$ & $\boldsymbol{L A T}$ & $\boldsymbol{A P}$ & $\boldsymbol{L A T}$ & $\boldsymbol{A P}$ & $\boldsymbol{L A T}$ & $\boldsymbol{A P}$ & $\boldsymbol{L A T}$ & $\boldsymbol{A P}$ & $\boldsymbol{L A T}$ \\
\hline BMD & 0.754 & 0.678 & 0.810 & 0.819 & 0.734 & 0.750 & 0.599 & 0.608 & 0.447 & 0.453 \\
BMC & 8.136 & 8.070 & 7.513 & 7.442 & 6.089 & 6.169 & 4.289 & 4.297 & 2.814 & 2.819 \\
\hline
\end{tabular}

$\mathrm{BMD}=$ Values in $\mathrm{g} / \mathrm{cm}^{2}$. BMC $=$ Values in grams . 
corresponds to the coronoid process and decreases progressively toward the distal extremity (Fig. 4) consistent with the gross anatomy. Lower BMD and BMC values are found in the distal region (ROI 5). The total BMD reveals significant statistical differences $(\mathrm{p} \leq 0.001)$, indicating that bone tissue distribution is not homogeneous, corresponding to the bone's trabecular architecture.

\section{DISCUSSION}

The higher BMD is found in the proximalintermediate region (ROI 2), which is the part of the ulna having the greater traction force.

Knowledge related to bone resistance is necessary for the understanding of the origin of fractures as well as to improve elbow fracture recovery (Heep \& Josten, 2007) and for the development of implants with the mechanical characteristics of native bone. Most studies have tended to investigate the humeral component, with the ulnar component being less examined (Goto et al., 2009).

Currently, there are various measurement instruments to quantify bone mass: Peripheral Quantitative Computer Tomography (pQTC) is the only one that is capable of differentiating between the cortical and trabecular bone, but it is very costly and emits more radiation than the DXA (Cann \& Genant, 1980). Broadband Ultrasound Attenuation (BUA) is the only instrument that analyses aspects of bone microarchitecture, such as elasticity and geometry, but it is less precise than DXA.

Dual energy X-ray absorptiometry (DXA) offers quantitative information on BMC and BMD (Wahner et al.). As previously reported (Hvid et al., 1985), there is a close relationship between bone mass and bone strength. Furthermore, it is capable of measuring the axial and appendicular skeleton, and with its low radiation and high precision, it is currently the method of choice for bone mass measurement.

The progressive decrease in BMC is consistent with the gross anatomy of the ulna. Literature reveals various studies on long bones, such as the femur, the tibia, the humerus and the radius (D'Amelio et al., 2002; Kawashima \& Uhthoff, 1991; Wahner et al.) but no references have been found regarding the study of BMD distribution in the ulna to describe the systematics of its make-up.

According to Wolf's law (Viladot, 2001), bone adapts its size, shape and structure to mechanical requirements. Additionally, Pauwels (1980) and Miralles (1998) have suggested that cortical bone mass is distributed along its axis in proportion to the amount of tension that it receives. In our analysis, we found a wider BMD in the intermediate-proximal region (ROI-2), corresponding to the region of the bone that is exposed to the mechanical flexion and to the transmission of weight charges while the superior member is in the extended position: three different soft tissue structures insert in or attach to the coronoid process, the articular capsule, the brachialis muscle tendon and the anterior band of the ulnar collateral ligament (Fowler \& Chung, 2006). Fractures have been seen in this region in elderly woman, occurring without trauma or falls (Tang \& Kumar, 2011). Furthermore, the transmission of weight charges travels through the coronoid process, situated in the proximal region (ROI-1), which presents the greatest BMC in both projections. Also, fractures of the coronoid process rarely occur as isolated injuries. They are more frequently found in impacts with the humerus, and their effect on the stability of the elbow is proportional to the amount of fractured coronoid. They are also associated with radial head fractures (Weber et al., 2009).

Some authors have agreed on the homogeneous nature of the different diaphyseal regions of the long bones under study (femur, humerus and tibia) (Fernandez Camacho et al.). As for the ulna, BMD reveals a more heterogeneous distribution, since statistical differences are found in all studied regions and on the entire bone.

The results obtained with the DXA technique revealed that BMD is in accordance with the arrangement of the trabecular system in the human ulna, as described previously by some authors (Gómez-Oliveros).

This study confirms that the higher mechanical solicitations in the ulna are found in the proximal extremity. Differences found in the ulna BMD offer an increased understanding of the construction systematics and their functional activity.

The bone structure of the ulna may also be studied in living individuals, a possible extension of this study which would serve to compare these results with those obtained in forearm densitometry studies (bone with soft tissues).

Due to frequent complications associated with reconstructive elbow surgery, implant loosening, periprosthetic fracture, implant failure, etc. (Kim et al., 2011), which are more common than in arthroplasty of other joints (Sanchez-Soltelo, 2011), the findings from this study may contribute to the improvement of elbow prosthesis. 
This study confirms the effectiveness of the methodology used to study ulna bone architecture. On the other hand, the utility of obtaining densitometric databases is growing in terms of application to the design of implants and prosthetics (robustness, adaptability, duration) taking into accounts the internal bone structure. Future studies should aim to expand upon this work, incorporating new variables such as the study in living subjects, considering age, gender, physical activity, etc. In conclusion, it has been found that bone densitometry, measured by the DXA technique, is useful for assessing the trabecular architecture of the human ulna.

AGUAdO-HENCHE, S.; CLEMENTE DE ARRIBA, C. \& CARRASCOSA-SÁNCHEZ, J. Análisis densitométrico de la ulna humana. Int. J. Morphol., 33(3):902-907, 2015.

RESUMEN: Este estudio describe la distribución de la masa ósea de la ulna humana madura. Su conocimiento de distribución puede proporcionar información a cirujanos ortopédicos para el tratamiento de fracturas a la vez que se avanza en la comprensión de las respuestas de los elementos de osteosíntesis durante la reparación ósea. Se utilizó una muestra de 41 ulnas secas, que se estudiaron mediante absorciometría dual fotónica de rayos-X (DXA) con un densitómetro Norland XR-26. Se emplearon dos proyecciones: anteroposterior y lateral. En ambas proyecciones se seleccionaron cinco regiones de interés: proximal (ROI 1), intermedio-proximal (ROI 2), intermedia (ROI 3), intermedio-distal (ROI 4) y distal (ROI 5). Los cálculos estadísticos se realizaron con los programas Stat Graphics Plus (versión 5.1) y SPSS (versión 15.0). Se obtuvieron los valores medios y desviaciones estándar de la densidad mineral ósea (DMO) y el contenido mineral óseo (CMO) en cada una de las regiones de interés y en ambas proyecciones. Se compararon los valores medios de todas las regiones usando la prueba t de Student para muestras pareadas. La mayor DMO se encontró en la región intermedioproximal (ROI 2) y en ambas proyecciones, mientras que la región que presentaba el mayor CMO fue la región proximal (ROI 1). Los valores más bajos, tanto de CMO como de DMO, en las dos posiciones del examen, correspondieron con la región distal (ROI 5). Al comparar cada una de las regiones con todas las restantes, encontramos que la DMO y el CMO muestran diferencias muy significativas $(\mathrm{p} \leq 0,001)$, lo que indica la naturaleza heterogénea de la distribución de la masa ósea en la ulna. La densitometría ósea mediante DXA es útil para establecer un esquema de construcción estructural de la ulna humana.

PALABRAS CLAVE: Densitometría; Ulna; Densidad mineral ósea; Contenido mineral óseo; Codo.

\section{REFERENCES}

Blake, G. M. \& Fogelman, I. Technical principles of dual energy x-ray absorptiometry. Semin. Nucl. Med., 27(3):210-28, 1997.

Cann, C. E. \& Genant, H. K. Precise measurement of vertebral mineral content using computed tomography. J. Comput. Assist. Tomogr., 4(4):493-500, 1980.

D’Amelio, P.; Panattoni, G. L. \& Isaia, G. C. Densitometric study of human developing dry bones: a review. J. Clin. Densitom., 5(1):73-8, 2002.

Fernandez Camacho, F. J.; Morante Martinez, P.; Rodríguez Torres, R.; Cortes García, A. \& Gomez Pellico, L. Densitometric analysis of the human calcaneus. J. Anat., 189(Pt. 1):205-9, 1996.

Fowler, K. A. \& Chung, C. B. Normal MR imaging anatomy of the elbow. Radiol. Clin. North Am., 44(4):553-67, 2006.

Goldberg, S. H.; Omid, R.; Nassr, A. N.; Beck, R. \& Cohen, M. S. Osseous anatomy of the distal humerus and proximal ulna: implications for total elbow arthroplasty. J. Shoulder Elbow Surg., 16(3 Suppl.):S39-46, 2007.

Gómez-Oliveros, L. Lecciones de Anatomía Humana. Osteología. Tercera parte: Miembros. Madrid, Marban, 1962.
Goto, A.; Murase, T.; Hashimoto, J.; Oka, K.; Yoshikawa, H. \& Sugamoto, K. Morphologic analysis of the medullary canal in rheumatoid elbows. J. Shoulder Elbow Surg., 18(1):33-7, 2009.

Heep, P. \& Josten, C. Biology and biomechanics in osteosynthesis of proximal humerus fractures. Eur. J. Trauma Emerg. Surg., 33(4):337-44, 2007.

Heinonen, A.; Mckay, H. A.; Whitall, K. P.; Forster, B. B. \& Khan, K. M. Muscle cross-sectional area is associated with specific site of bone in prepubertal girls: a quantitative magnetic resonance imaging study. Bone, 29(4):388-92, 2001.

Hsieh, Y. F. \& Turner, C. H. Effects of loading frequency on mechanically induced bone formation. J. Bone Miner. Res., 16(5):918-24, 2001.

Hvid, I.; Jensen, N. C.; Bünger, C.; Sølund, K. \& Djurhuus, J. C. Bone mineral assay: its relation to the mechanical strength of cancellous bone. Eng. Med., 14(2):79-83, 1985.

Kawashima, T. \& Uhthoff, H. K. Pattern of bone loss of the proximal femur: a radiologic, densitometric, and histomorphometric study. J. Orthop. Res., 9(5):630-40, 1991.

Kim, J. M.; Mudgal, C. S.; Konopka, J. F. \& Júpiter, J. B. 
Complications of total elbow arthroplasty. J. Am. Acad. Orthop. Surg., 19(6):328-39, 2011.

Miralles, R. Biomecánica Clínica del Aparato Locomotor. Barcelona, Masson, 1998.

Pauwels, F. Biomechanics of the Locomotor Apparatus. Contribution on the Functional Anatomy of the Locomotor Apparatus. New York, Springer-Verlag, 1980.

Sanchez-Sotelo, J. Total elbow arthroplasty. Open Orthop. J., 5:11523,2011

Schoenau, E.; Land, C.; Stabrey, A.; Remer, T. \& Kroke, A The bone mass concept: problems in short stature. Eur. J. Endocrinol., 151 (Suppl 1):S87-91, 2004.

Tang, Z. H. \& Kumar, V. P. Alendronate-associated ulnar and tibial fractures: a case report. J. Orthop. Surg. (Hong Kong), 19(3):370-2, 2011.

Tanck, E.; Homminga, J.; van Lenthe, G. H. \& Huiskes, R. Increase in bone volume fraction precedes architectural adaptation in growing bone. Bone, 28(6):650-4, 2001.

Tsujio, M.; Mizorogi, T.; Kitamura, I.; Maeda, Y.; Nishijima, K.; Kuwahara, S.; Ohno, T.; Niida, S.; Nagoya, M.; Saito, R. \& Tanaka, S. Bone mineral analysis through dual energy X-ray absorptiometry in laboratory animals. J. Vet. Med. Sci., 71(11):1493-7, 2009.

Viladot, A. Lecciones Básicas de Biomecánica del Aparato Locomotor. Barcelona, Springer, 2001.

Wahner, H. W.; Eastell, R. \& Riggs, B. L. Bone mineral density of the radius: where do we stand? J. Nucl. Med., 26(11):1339-41, 1985.

Weber, M. F.; Barbosa, D. M.; Belentani, C.; Ramos, P. M.; Trudell, D. \& Resnick, D. Coronoid process of the ulna: paleopathologic and anatomic study with imaging correlation. Emphasis on the anteromedial "facet". Skeletal Radiol., 38(1):61-7, 2009.

Windisch, G.; Clement, H.; Grechenig, W.; Tesch, N. P. \& Pichler, W. The anatomy of the proximal ulna. J. Shoulder Elbow Surg., 16(5):661-6, 2007.
Correspondence to:

Soledad Aguado-Henche, MD PhD

Department of Surgery

Anatomy and Social Medical Sciences

University of Alcalá

Ctra Madrid-Barcelona km. 33600

28871 Alcalá de Henares

Madrid

SPAIN

Email: soledad.aguado@uah.es

Received: 26-11-2014

Accepted: 29-05-2015 